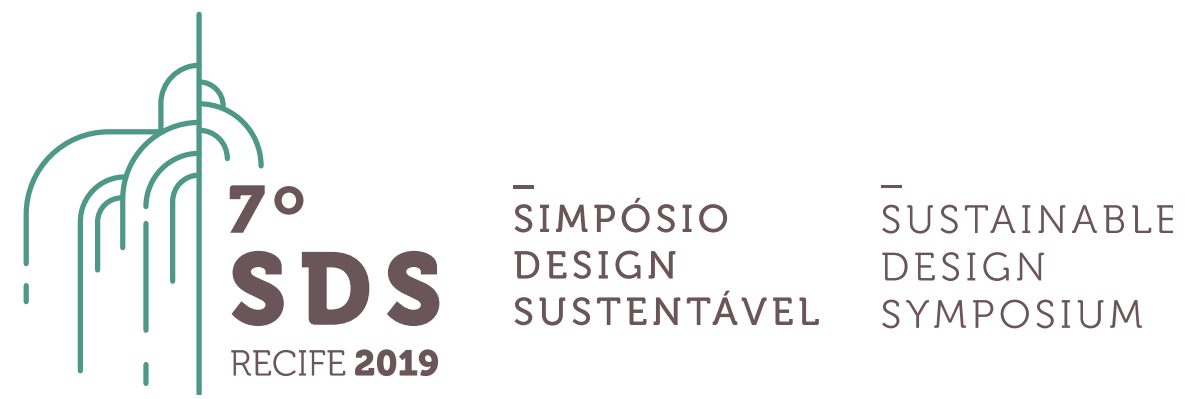

\title{
LUGAR CASA: espaço emocionalmente sustentável
}

\author{
Nadja Maria Mourão ${ }^{1}$, Ana Célia Carneiro Oliveira ${ }^{2}$, Rita de Castro Engler ${ }^{3}$ \\ ${ }^{1}$ Mestra e doutoranda em Design PPGD/UEMG; Professora de Design de Ambientes UEMG; Membro do CEDTec - \\ Centro de Estudos em Design e Tecnologia da Escola de Design/UEMG. \\ E-mail: nadja.mourao@uemg.br. \\ ${ }^{2}$ Mestra em Design PPGD/UEMG; Professora de Design de Ambientes UEMG; Membro do CEDTec - Centro de Estudos \\ em Design e Tecnologia da Escola de Design/UEMG. \\ E-mail: anaceliadesign@gmail.com. \\ ${ }^{3}$ PhD Gestão de Inovação Tecnológica/ECP França; Professora PPGD/UEMG e coordenadora do CEDTec - Centro de \\ Estudos em Design e Tecnologia da Escola de Design/UEMG. \\ E-mail: rita.engler@gmail.com.
}

Resumo. O ser humano carrega suas experiências em ações individuais ou coletivas. A casa, lugar de vivência, ajuda a construir narrativa a respeito da trajetória de vida. O design afetivo apresenta-se como uma vertente metodológica explorada e que permite muitas possibilidades. Nesse contexto, o design afetivo se apresenta como uma vertente metodológica recentemente explorada e que permite possibilidades significativas. A proposta de investigação sobre a casa, tem como objetivo refletir sobre o significado afetivo daquilo que se denomina lar. Busca-se analisar a abrangência de pesquisa no campo de ação do design afetivo e sua função social. Realiza-se um estudo sobre a sustentabilidade ambiental e social (sustentabilidade afetiva), a partir dos conceitos da economia circular no ambiente residencial. Os bens materiais conservados em estrutura familiar por gerações seguem as diretrizes para a economia circular e podem ser considerados espelhos de experiências da passagem do tempo. A metodologia é realizada pela pesquisa bibliográfica de contextos temáticos e contemporâneos de sustentabilidade dentro da dimensão do design circular, do design afetivo, da sustentabilidade afetiva e da preservação da memória relacionada a casa. Desta forma, são investigados as denominações e o contexto das residências e suas relações com a sustentabilidade. Em análise sobre os espaços habitacionais, verificou-se que os ambientes residenciais ecléticos se popularizam. O que contribui para a sustentabilidade ambiental e social, considerando os objetos e os ambientes das casas, pelo incentivo do Design Circular, em Cradle to Cradle. Assim, a sustentabilidade afetiva também é uma área em desenvolvimento, utilizada por designers que seguem conceitos de responsabilidade social. As relações da memória familiar contribuem para preservação dos valores materiais e emocionais. No ambiente da casa, os significados se modificam conforme o contexto cultural.

Palavras-chave. Espaço casa; design afetivo; sustentabilidade afetiva; felicidade; memória. 


\section{Introdução}

O ser humano vive rodeado de lugares e objetos idealizados para servir e agradar da forma que lhe convém. Além da função prática, os objetos e ambientes são criados para estimular sentimentos e sensações. Damazio (2015) expõe que eles são os meios para o indivíduo interagir com o espaço físico e artefatos compartilhados, que consagram a inclusão da pessoa no grupo social, ou seja, para se tornar mais natural à sociedade em que vive.

Nesse contexto, o design afetivo se apresenta como uma vertente metodológica recentemente explorada e que permite possibilidades significativas. A proposta de investigação a casa, lugar de vivência familiar, tem como objetivo refletir sobre o significado afetivo daquilo que se denomina lar. Busca-se analisar a abrangência de pesquisa no campo de ação do design afetivo e sua função social. Realiza-se um estudo sobre a sustentabilidade ambiental e social (sustentabilidade afetiva), a partir dos conceitos da economia circular no ambiente residencial. Os bens materiais conservados em estrutura familiar por gerações seguem as diretrizes para a economia circular e podem ser considerados espelhos de experiências da passagem do tempo.

No final de um dia de trabalho, há um ditado popular que diz que "voltar para a casa é uma felicidade". O tema felicidade, em tempos atuais, tornou-se uma das principais variáveis para a análise do desenvolvimento sustentável das nações. Utiliza-se de indicadores econômicos que avaliam o progresso genuíno, ou seja, a qualidade de vida (DESMET e POHLMEYER, 2013).

Diener e Seligman (2002) realizaram uma pesquisa sobre a felicidade direcionada aos estudantes e concluíram que aqueles que eram pessoas mais sociáveis, também se consideravam mais felizes. Eles constataram que pessoas de lugares diferentes do planeta, consideram a felicidade um objetivo fundamental. Observaram que a felicidade estimula o sistema imunológico, a criatividade e influencia o ambiente.

Outros pesquisadores buscaram respostas para as questões de consumo com reflexos na felicidade. Kashdan e Biswas-Diener (2016) relatam que o segredo da felicidade é uma preocupação da sociedade no mundo contemporâneo. As pessoas acreditam que a estabilidade financeira proporciona a oportunidade de se concentrar no crescimento pessoal. Ou seja, se trabalha mais para ter acesso a aquisição de objetos e ter qualidade de vida, principalmente nas residências. Cloninger (2006) pesquisou as possibilidades do dinheiro, do poder e da fama de realmente proporcionar a felicidade. Ele constatou o "ter" conduz aos sentimentos efêmeros, o que realmente contribui para a felicidade das pessoas é o que o desenvolvimento do caráter pode fazê-lo. Ou seja, "a felicidade é uma emoção basicamente caracterizada por um estado emocional positiva, com sentimentos de bem-estar e de prazer, associados à percepção de sucesso e à compreensão coerente e lúcida do mundo" (FERRAZ et al.,2007).

Contudo, os espaços residências são células que refletem o comportamento familiar. 0 sentimento de felicidade contém, em essência, o bem-estar. Uma casa pode contribuir com a sustentabilidade de forma planejada ou adaptada para evitar o consumo desnecessário e reduzir custos energéticos. Sachs (2008) aborda cinco pilares da sustentabilidade: social, econômico, ecológico, espacial e cultural. Expõe a necessidade de afastar a dependência técnica e cultural e valorizar a cultura local e seus recursos. Uma proposta de democracia participativa, com desenvolvimento endógeno e equidade social, na busca por melhorias de condições da sociedade.

Este trabalho busca conhecer os espaços habitacionais, ambientes domésticos e funções sociais, como estudo sobre sustentabilidade ambiental e social (sustentabilidade afetiva) em economia circular, e as relações da memória como fator de preservação do ambiente. A metodologia se realiza pela pesquisa bibliográfica de contextos temáticos e contemporâneos da 
sustentabilidade na dimensão do design circular, do design afetivo e sustentabilidade afetiva, e na preservação da memória relacionada a uma casa. "Como limitação do método proposto pode ser levantada a necessidade de o pesquisador ter conhecimento prévio sobre o tema de pesquisa. Durante todo o processo é necessária a intervenção do autor para identificação das palavraschave e realização das filtragens" (TREINTA et al., 2012, p. 4). Dessa forma, são analisadas as denominações e o contexto de "residência-moradia-casa" e suas relações com a sustentabilidade, apresentadas a seguir.

\section{O Ambiente residencial eclético a sustentabilidade}

Preservar o padrão de vida e ao mesmo tempo enxergar o crescimento tecnológico sem prejudicar os recursos naturais, tornou-se um grande desafio para a humanidade. "Pensar globalmente e agir localmente" ainda é uma proposta de paradigma para a humanidade (PNUD, 1994). Design sustentável é uma condição atual para qualquer projeto em design em serviços e produtos. A questão ainda é complexa em relação às adaptações de produtos, de materiais e processos de consumo excessivo e o conhecimento dos usuários. Contudo, o alinhamento com a responsabilidade socioambiental pode satisfazer aos clientes conscientes da exaustão dos recursos do planeta.

A fundamentação eclética, a teoria do agir organizacional representou o alicerce último, mas não menos importante do paradigma da sustentabilidade, uma vez que por ela se confirmou o caráter eclético, dialógico e pluralista desse corpo paradigmático (MUNCK; SOUZA, 2011).

Em busca da identificação do lugar de residência (casa e seus ambientes e artefatos, relacionada à vida humana) é possível relatar a passagem desses na história contemporânea. 0 estudo do design de ambientes ecléticos compreende uma combinação de diferentes elementos e técnicas de diferentes épocas. Trata-se de uma combinação capaz de criar uma composição no mesmo espaço entre o emocional e o principal. Em um ambiente eclético é possível combinar diferentes estilos, selecionados e harmoniosamente colocados. "O ecletismo é um fenômeno mais vasto que requer uma abordagem interdisciplinar" (FABRIS, 1993, p. 135). O termo durante o século XIX foi utilizado como sinônimo um estilo sem personalidade, sem originalidade e, até mesmo, de imitação.

Alguns teóricos relacionam o ser eclético ao ser híbrido. O hibridismo é uma contração entre tradições diferentes, "são uma poderosa fonte criativa, produzindo novas formas de cultura, mais apropriadas à modernidade tardia que às velhas e contestadas identidades do passado" (HALL, 2006, p. 91). O eclético, em síntese, é ter afeto por muitos estilos, com elementos semelhantes ou não, mas juntos - recortes e colagens culturais. Os recortes de vários estilos também se constituem em um estilo único, uma identidade.

Conforme Kandjnsky (1991, p.120), "o essencial na questão da forma é saber se ela nasceu de uma necessidade interior ou não". Assim, se o design se atentar a forma no mundo humano e o homem como essência de si mesmo, ele será capaz de criar formas, diferentes ideias e gerar soluções para os anseios deste homem que quer ter o seu lugar no universo.

$\mathrm{Na}$ figura 1, apresenta-se um modelo de ambiente residencial eclético. 0 projeto se constitui em materiais diversos, referências de elementos da natureza, produtos artesanais e industrializados, mas com padrões e formas equilibradas. 
Figura1 - Modelo de ambiente residencial eclético.

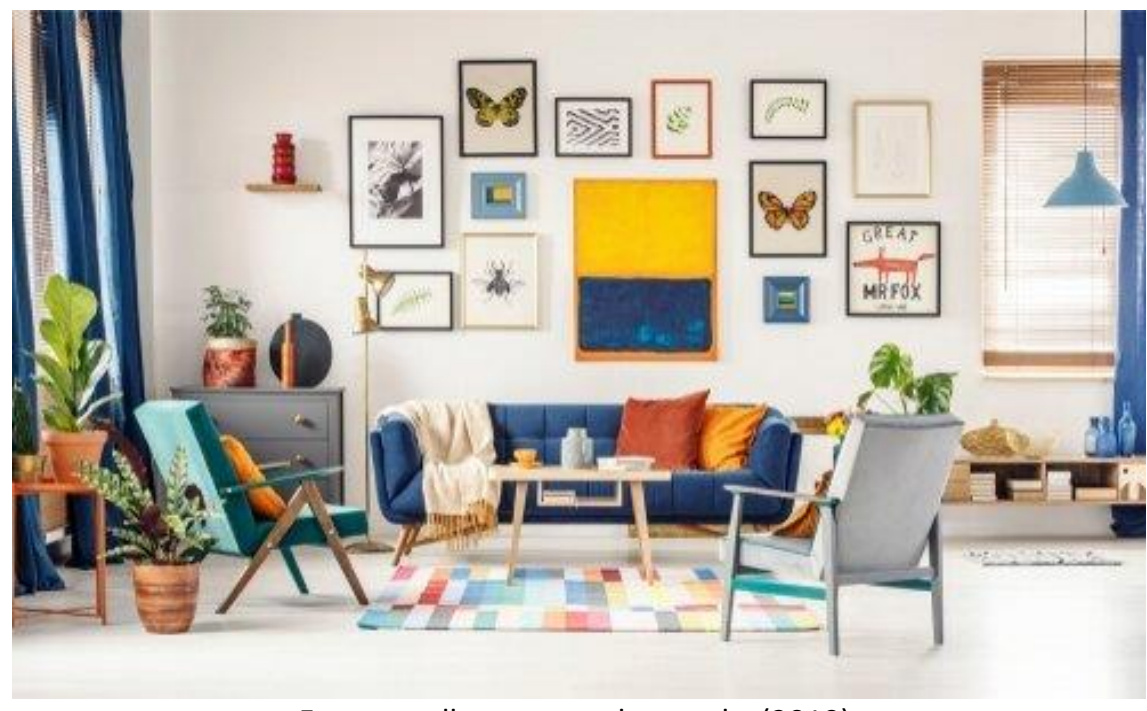

Fonte: melhorcomsaude.com.br (2019).

O ecletismo no design transporta um sentimento nostálgico. As marcas de vivência podem acrescentar autoridade aos lugares e seus artefatos, como depressões em superfícies, descascados e misturas de materiais acolhedores. São lugares que ajudam a perpetuar o passado e a construir narrativas a respeito da trajetória de vida daqueles que o preservaram, estabelecendo um equilíbrio visual na combinação de todos os elementos. Esta cultura se tornou uma questão de herança ou gosto cultural do indivíduo que a habita. "As pessoas pegam e escolhem de acordo com a sua classe, gênero, crença religiosa, etnia e cidadania, assim como de acordo com todas as exigências de sua própria formação pessoal, em um supermercado cultural que faz intensa propaganda" (MATHEWS, 2002, p. 44).

\section{A casa e a relação com a Economia Circular}

Uma economia circular familiar, os bens podem ser considerados produtos de alto nível de utilização e de valor em potencial; um ciclo contínuo de valor emocional, dissociado do consumismo. Uma casa emocionalmente sustentável, a ideia circular é assegurada pela redução, reutilização, recuperação e reciclagem de materiais e da energia. Materializa-se na maximização da reutilização instrumentada pela afetividade e memória.

Novas formas de relação entre a profissão do design e as questões ambientais surgem em busca de soluções. O Cradle to Cradle, ou "do berço ao berço", é um conceito de design desenvolvido por William McDonough e Michael Braungart. A proposta consiste na não geração de resíduos no processo de produção e consumo dos produtos. Baseia-se nos sistemas de fluxo de nutrientes da natureza não há desperdício e não existe um fim, pois com o término de um ciclo outro se inicia. Gejer e Tennenbaum (2017) afirmam que o modelo Cradle to Cradle propõe sistemas naturais interdependentes tendo em vista a geração de processos saudáveis e circulares, e assim, gerando um desenvolvimento ambiental, social e econômico. "Os três princípios fundamentais para o design e sistemas eco-efetivos são: resíduos são nutrientes, utilização da fonte solar ilimitada e celebrar a diversidade" (GEJER; TENNENBAUM, 2017, p.1).

Na figura 2, apresenta-se o primeiro modelo em Casa Circular, em São Paulo executado pela empresa Ideia Circular. Houve um cuidado para que os produtos empregados pudessem continuar circulando de forma segura e saudável tanto para a natureza quanto para os seres humanos. A casa foi montada com painéis com componentes pré-fabricados, que permitem a customização, bem como ampliações, reduções ou desmembramento dos materiais que podem ser transformados e obter novas utilizações. Não foram utilizadas resinas que emitem gases 
tóxicos, nem colas ou argamassa, o que permite que cada material possa retornar ao seu ciclo de forma saudável. Na figura 2, apresentam-se os esquemas da casa sob os aspectos: ciclos de água, energia e nutrientes, biodiversidade e saúde.

Figura 2 - Esquemas dos ciclos Cradle to Cradle na primeira Casa Circular
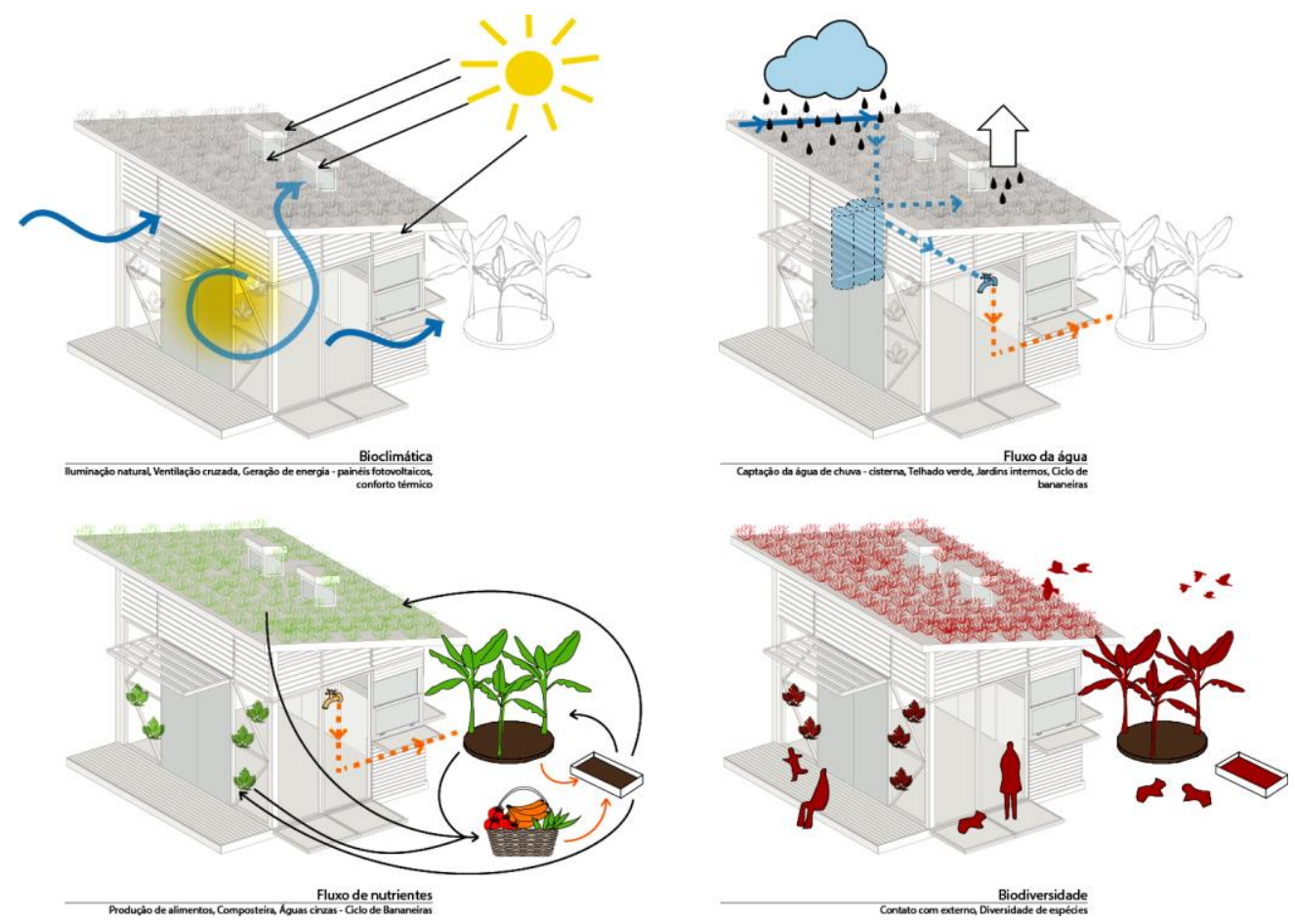

Fonte: Idea Circular (2018).

Dessa forma, a ideia do Design Circular é estabelecida desde a criação de qualquer produto. Na Itália, este conceito se aproxima do Design Sistêmico, exposto por Luigi Bistagnino (2009), que busca repensar o mundo urbano, desde o projeto de cidades e casas até o de objetos do cotidiano. No Brasil, ainda são ideias incipientes, discutidas e adotadas por alguns pioneiros.

\section{A casa e a sustentabilidade afetiva}

O ser humano, por suas vivências nas moradias carrega impressões, aprendizagens e ensinamentos, em ações individuais ou coletivas. Além disso, há uma relação afetiva entre o usuário, lugar e o artefato. Nesse contexto, $\mathrm{O}$ design afetivo se apresenta como uma aba metodológica contemporânea, que permite diversas possibilidades. $O$ design afetivo se concentra no usuário, pois de acordo com Freire (2009), este passou a ser o elemento norteador do processo de design. A partir das mudanças de necessidades do ser humano, alterou-se o foco do produto em experiência de uso e o que esse uso provoca em cada indivíduo.

Quanto à permanência do produto no ambiente, Csikszentmihalyi e Rochberg-Halton (1981) definem o termo "cultivação" como referência dessa circunstância. Trata-se de um método em que um ser humano confere atenção e se dedica física e mentalmente a alguma coisa, como aos objetos. Eles passam a ter novos valores, impregnados de vivências e elementos culturais. Os valores induzem ao contexto do tempo, do ambiente e da relação pessoa-produto. Para os autores, o artifício de cultivação pode fazer o homem redescobrir frequentemente sua intenção de dedicação a preservação do lugar e seus artefatos, afirmando sua presença física. 
Para Borjesson (2008), o trabalho do design sustentável traça uma linha dupla entre o projeto e o indivíduo e aponta para diversas questões que não se delimitariam a qualidade dos produtos. Ou seja, "os aspectos imateriais que influenciam a nossa experiência com o produto; a estética, o emocional, o significado" (BORJESSON, 2008, p.3).

$\mathrm{O}$ autor relata que muitos designers passaram a observar quais os aspectos imateriais que beneficiam o apego aos lugares e artefatos, por muitos anos. Verificaram também que há dificuldades de isolar as características físicas que norteiam o indicador de durabilidade ou eternidade destes ambientes. Alguns deles alcançam durabilidade além das próprias condições físicas, permanecendo por várias gerações como referências, e ultrapassando limites e fronteiras territoriais e culturais. Há diversas abordagens relacionadas ao estilo de vida das pessoas. Assim, o comportamento das pessoas com os objetos pode conduzir o indicador do produto como durável.

Segundo Oliveira e Mourão (2018), na história dos oratórios de Minas Gerais, símbolo da religiosidade, a imagem do santo que protegia a família (preservado em oratório) era transferida de mãe para filha. A imagem do santo protetor seria colocada na residência da herdeira, passando de geração em geração. Estes objetos de fé, com o sabor mágico e místico por diversas mãos, se difundiram na história do povo brasileiro, pelo processo de transportação cultural, inseridos pelo imaginário estético popular, oriundos de fontes portuguesas, desde o período colonial. Atualmente, estes símbolos de fé recebem novas roupagens ou são adaptados em nichos em ambientes familiares.

A figura 3 apresenta exemplos de oratório e imagens religiosas em ambientes residenciais.

Figura 3 - Oratórios e imagens religiosas em residências

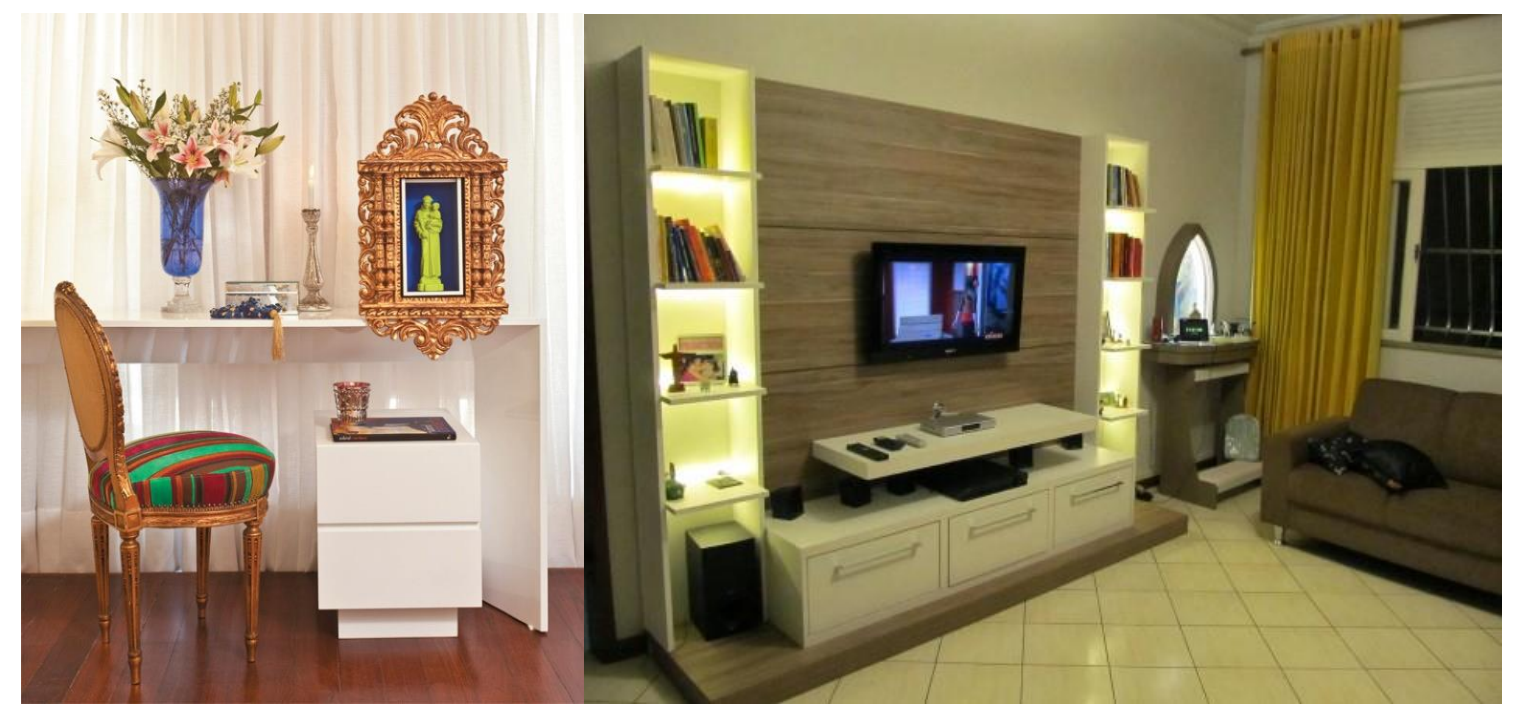

Fonte: decoracaoearte.com.br (2019).

Este é um exemplo da importância de oratórios para santos protetores da família. Contudo, há inúmeros exemplos de objetos que permanecem como utilitários ou peças decorativas nas residências: peças de cerâmicas, poltronas ou cadeiras que alguém usou por muito tempo, quadros decorativos e até mesmo cafeteiras. Os artefatos que envolvem o ser humano arranjam com que suas lembranças se conservam vivas e estes fazem uma junção com o seu passado, representam uma experiência vivida dando a aparência de ininterrupção e pertencimento.

Relembrar o passado é crucial para nosso sentido de identidade: saber o que fomos confirma o que somos. Nossa continuidade depende inteiramente da memória; recordar experiências passadas nos liga a nossos selves anteriores, por mais diferentes que tenhamos nos tornados (LOWENTHAL,1998, p. 83). 
Em seu trabalho, Borjesson (2008) diz que a ideia de durabilidade estaria obsoleta e passa a utilizar o conceito de sustentabilidade afetiva ao preceito holístico. "A sustentabilidade não pode ser reduzida à ideia de sustentação, mas significa contribuição para superar e continuar o bemestar dos humanos, sem distinções entre o corpo e a mente". (BORJESSON, 2008, p. 10). Desse modo, ampliam-se os campos de estudo do ciclo de vida do produto, conduzindo à reflexão da forma de vivenciar, por memória afetiva e cognitiva dos indivíduos.

\section{Memória da casa em família: saberes culturais}

A memória humana é sustentada por lembranças construídas, conexões afetivas, alegrias, desejos, apegos, luto e tantos outros sentimentos íntimos. $\mathrm{O}$ ato de rememorar, segundo Brandão (1990, p. 51), possibilita a ressignificação. É uma ação que une o passado, o presente e o futuro, que se harmonizam reforçando a sensação de pertinência a um grupo de origem e a um destino. $A$ vida de ser humano pode ter uma bela história de vivências e relacionamentos familiares que não voltam mais, sejam vindas da infância, adolescência, idade adulta ou na própria velhice.

Em linguística, "a palavra casa muitas vezes significa homem" (MUSSI; CÔRTE, 2010, p. 234), rica em alegria e cultura. No campo da psicologia, ela se estabelece no vínculo do ser humano com os acontecimentos, considerando inclusive que, os fatos se constituem em lugares e momentos. A casa representa o ser humano em sua essência; de certa forma, é a pedra angular de sua personalidade. A representação de uma casa leva em conta as interações entre a natureza e a cultura, entre o inato e o adquirido, entre o indivíduo e a sociedade. Segundo Biedermann (1993), frequentemente o ser humano é a casa, assim entendida como a identidade do homem.

O lugar casa é aquele que se ocupa, por onde se passa ao qual se tem acesso e que fixa as construções e pensamentos do passado para que reapareça esta ou aquela categoria de lembranças. Ele se torna um referencial para a memória. O termo casa é utilizado como referência à estrutura física, constituída muitas vezes de tijolos, cimento e memória. Por isso, de acordo com Rybczynski (2002), para a recuperação das recordações do passado, precisa-se situar o meio tangível (o ambiente) que cerca o ser humano e onde a memória se conserva. As casas têm histórias para contar e podem ser associadas a pessoas e acontecimentos. A expressão da afetividade se torna um modo do ser humano se comunicar na sociedade, deixando de ser apenas um valor pessoal. A valorização dos saberes culturais ligados às memórias cria experiências e emoções aplicáveis às novas gerações. Nesse contexto, de acordo com Mussi e Côrte (2010), pode-se pensar que as casas são lugares de memória, que influenciam na percepção que as pessoas têm em especial da cidade que habitam. Em muitos casos, a manutenção das casas localizadas em centros urbanos se constitui lugares de preservação de lembranças dos modos de vida e tempos vividos no passado. Atua como meio de construção de uma nova dinâmica de vida, possivelmente diversa do estilo de vida comum na atual conjuntura social.

Grubits (2003) diz que a pessoa se relaciona com a casa por meio das relações com os familiares e pelo ambiente construído. "A casa é construída, elaborada, edificada pela mão do homem. No seu estado atual, sua concepção é o resumo de todas as aquisições efetuadas ao longo das diferentes etapas do desenvolvimento humano" (GRUBITS, 2003, p.99).

Royer (1989) afirma que a casa estabelece um padrão dos mais complexos e, por isso, mais difíceis de comentar. Para o autor francês, a casa é o símbolo de todas as "peles" consecutivas que envolvem o ser humano - o seio materno, corpos, família, universo - e vão se afeiçoando. É o termo mais cheio de ressonância afetiva, mais capaz de desencadear lembranças, sonhos, paixões: a casa da infância, a casa da família, a casa das férias, a casa dos sonhos matrimoniais, a casa de retiro, a última moradia. Para cada ser humano sua casa tem seus cheiros, recantos, ruídos e silêncios, fogos e águas, luzes, penumbras intimidantes ou favoráveis à ponderação e as confissões. A imagem da casa, feliz ou não, o acompanha ao longo de sua vida. 
Segundo Bosi (2003), tudo em uma casa que abriga uma família fala: o teto, o fogo, a mobília, as esculturas, as pinturas. O tempo acresce seu valor: a arca passa à velha arca. A casa onde ocorre o desenvolvimento de uma criança é povoada de objetos de valores significativos. Estes se condicionam ao contexto do uso e circunstâncias ao longo do tempo, com o mesmo significado vivenciado pela criança. $O$ desenraizamento do ambiente estimula o esquecimento das vivências.

O homem, como resultado da experiência íntima com o seu mundo interno e com outras pessoas do mundo externo, estabelece o lugar que habita a fim de conformá-lo com as necessidades que não são apenas biológicas, mas também sociais, culturais e psicológicas. A casa é, neste sentido, muito mais do que um simples abrigo do corpo. A ela são atribuídos sentidos, significados, valores e afetos. Para Gonçalves (2007), toda pessoa tem uma história social, cultural e ambiental. Ou seja, a pessoa, na sua história social, carrega fatos, lembranças, relações que foram admiráveis. Esses elementos recebem valor simbólico se analisados sob o ponto de vista da cultura. O valor simbólico é o sentido que o sujeito dá para todas as coisas, materiais e imateriais, relacionadas ao contexto físico, emocional e espiritual. A casa tem o seu valor simbólico para o homem, que fundamenta a formação do sujeito e de sua subjetividade.

Na figura 4, observa-se a relação de uma família de imigrantes italianos com a casa. O italiano, Michele Mosena (nascido em Belluno/Itália), com a esposa e alguns dos 10 filhos, em 1882, no distrito de Arcoverde/Serra Gaúcha. Imagem onde a casa é parte da formação familiar e conquista de todos os membros.

Figura 4 - Família Mosena e sua casa em 1882.

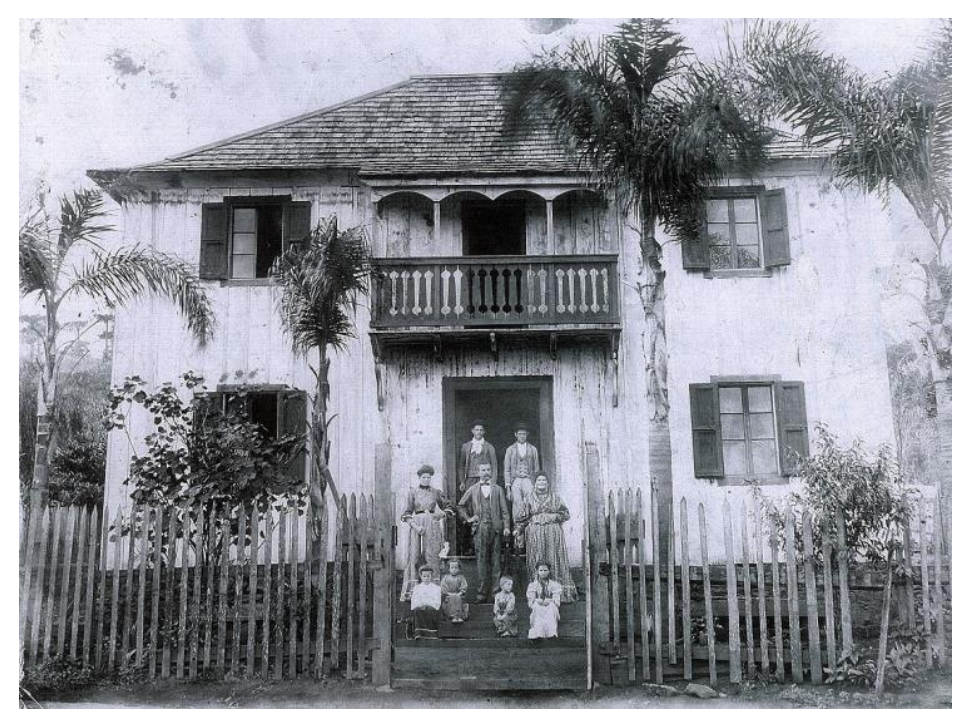

Fonte: clicrbs.com.br(2019).

Segundo Geertz (1989), o homem é um ser envolto na malha dos significados que ele mesmo teceu. Pode-se dizer que "cultura" se refere ao significado que um grupo social dá à sua experiência, abrangendo aqui ideias, crenças, costumes, artes, linguagem, moral, etc. Deve-se "atentar para o comportamento e com exatidão, pois, é através do fluxo do comportamento - ou mais precisamente da ação social - que as formas culturais encontram articulação". Segundo o autor "elas encontram-na também, certamente, em várias espécies de artefatos e vários estados de consciência" (GEERTZ, 1989, p. 27). 
Conforme Morgado (2014), a cultura é toda a vida de um povo e a herança social que o individuo adquire de seu grupo. É considerada também como parte do ambiente que o próprio homem criou. Tomada em seu amplo sentido etnográfico, é todo complexo que inclui conhecimento, crença, arte, moral, lei, costume e quaisquer outras capacidades e hábitos adquiridos pelo homem na condição de membro da sociedade.

A cultura é dinâmica, se recicla constantemente incorporando novos elementos, abdicando antigos; mesclando os dois transformando-os num terceiro com novo sentido. "Cultura não é acessório da condição humana, antes é sua essência. O ser humano é humano porque produz cultura, dando sentido à experiência objetiva e subjetiva" (GRUMAN, 2012, p.199). É nessa perspectiva que se compreende a cultura e suas manifestações da realidade, enquanto expressões a nível simbólico, baseado na experiência vivenciada pelos segmentos na sua experiência cotidiana.

Segundo Vallejo (1975), uma casa nasce para o mundo quando as pessoas passam a residir nela. Para este autor, a relação entre moradia e habitantes, está além da necessidade de abrigo. Surge uma relação de simbiose entre moradores e casas, vínculos recíprocos de formação identitária. Cada ser humano pode, então, conferir significados e colocar associações de intimidade com o lugar onde mora. Culturalmente, a habitação resume os alcances humanos ao longo do tempo, refletindo seu modo de influência mútua com o meio ambiente, a enriquecimento tecnológico do grupo e as particularidades locais (RAPOPORT, 1972).

\section{Análises e considerações}

É inegável que o ser humano vive um momento que pede por mudanças das relações do ser humano com os ambientes e objetos. Relaciona-se a felicidade com a aquisição de bens materiais. Constata-se a preocupação de alguns autores e pesquisadores pela emergência de um novo agir das pessoas e suas condutas com vínculos aos lugares e seus artefatos.

Em análise sobre os espaços habitacionais, verificou-se que os ambientes residenciais ecléticos se popularizam. O que contribui para a sustentabilidade ambiental e social, considerando os objetos e os ambientes das casas, pelo incentivo do Design Circular, em Cradle to Cradle. Assim, a sustentabilidade afetiva também é uma área em desenvolvimento, utilizada por designers que seguem conceitos de responsabilidade social.

As relações da memória familiar contribuem para preservação dos valores materiais e emocionais. No ambiente da casa, os significados se modificam conforme o contexto cultural. Consta-se que objetos como oratórios e santos permanecem na cultura religiosa das casas, como outros objetos. Os seres humanos ainda precisam estar incluídos de um grupo culturalmente identificado. Eles precisam esclarecer quais são seus hábitos e gostos para que a sociedade possa reconhecê-lo, como parte deste grupo.

As casas são lugares de memória, que influenciam na percepção que as pessoas adquirem, de forma especial, da cidade e região que habitam. Em muitos casos, a manutenção das casas localizadas em centros urbanos se constitui lugares de preservação de lembranças dos modos de vida e tempos vividos no passado, também servindo como meio de construção de uma nova dinâmica de vida, possivelmente diversa do estilo de vida comum na atual conjuntura social.

Contudo, manter a vida útil dos objetos e dos ambientes residenciais também é uma forma de contribuir com a sustentabilidade. A casa, dessa forma, se torna uma fonte de ressignificação dos objetos, que adquirem novas referências familiares entendendo a vida útil dos produtos. Dessa forma, as contribuições do design afetivo devem ser cultivadas, no sentido contrário ao consumismo. 


\section{Referências}

BIEDERMANN, H. Dicionário Ilustrado de Símbolos. São Paulo: Melhoramentos, 1993.

BISTAGNINO, L. Design sistêmico. Progettare la sostenibilità produttiva e ambientale, Turim: Slow Food, 2009.

BORJESSON, K. Affective Sustainability. Is this what timelessness really means? In: /8Undisciplined! Design Research Society Conference 2008. Sheffield Hallan Univesity Research Archive (SHURA), Julho/2008

BOSI, E. Memória e Sociedade: lembranças de velhos. São Paulo: Tao, 2003.

BRANDÃO, V.M.A.T. Os Fios da memória na trama da cultura. Revista Kairós Gerontologia, Ano 2, n.2. São Paulo: EDUC/PUC-SP.CANTELLI, Ana Paula, 1990.

BRAUNGART, M.; MULHALL, D.; GEJER, L.; TENNENBAUM, C. Do Berço ao Berço e a lógica de produzir com foco na reutilização. Ideia circular.com. (https://www.ideiacircular.com/do-bercoao-berco-e-a-logica-de-produzir-com-foco-na-reutilizacao/)

BRAUNGART, Michael; MCDONOUGH, William. Cradle to Cradle: criar e reciclar ilimitadamente.

(Trad.) BONALDO, F. Rio de Janeiro: Editora GG BR - Gustavo Gili, 2013.

CLICRBS.COM.BR. (http://wp.clicrbs.com.br/memoria/tag/imigracao-italiana/?topo=35,1,1,,,35).

CLONINGER, C.R. The science of well-being: an integrated approach to mental health and its disorders. World Psychiatry 5, p. 71-76, 2006.

CSIKSZENTMIHALYI, M; ROCHBERG-HALTON, E. The meaning of things: Domestic Symbols and the self. Cambridge: Cambridge University Press, 1981.

DAMAZIO, V. Artefatos de memória da vida cotidiana: um olhar interdisciplinar sobre as coisas que fazem bem lembrar. 2005. 285f. Tese (Doutorado em Ciências Sociais) - Universidade do Estado do Rio de Janeiro, Rio de Janeiro, 2005.

DESMET, P. M. A.; POHLMEYER, A. E. Positive Design: An Introduction to Design for Subjective Well-Being. Internacional Jornal of Design Vol. 7 No. 3, 2013.

ECLETISMO. In: Enciclopédia Itaú Cultural de Arte e Cultura Brasileira. São Paulo: Itaú Cultural, 2019. Enciclopediaitaucultural.com. (http://enciclopedia.itaucultural.org.br/termo357/ecletismo)

FABRIS, A. Arquitetura eclética no Brasil: o cenário da modernização. In: Anais do Museu Paulista Nova Série, 1993. (http://www.scielo.br/pdf/anaismp/v1n1/a11v1n1.pdf).

FERRAZ, R. B. et al. Felicidade: uma revisão. Revista Psiquiatria Clínica. v. 34, no5, p.234-242, 2007.

FREIRE, K. Reflexões sobre o conceito de design de experiências. Reflections upon the experience design concept. Strategic Design Research Journal, 2009.

GEERTZ, Cl. A interpretação das Culturas. Rio de Janeiro, RJ: LCT, 1989. Gerontologia, 2. São Paulo: EDUC/NEPE-PUC-SP, 1990.

GEJER, L.; TENNENBAUM, C. Os 3 princípios do design circular Cradle to Cradle. São Paulo: Ideia Circular, 2017. (https://www.ideiacircular.com/casa-circular-mostra-na-pratica-o-que-e-umedificio-circular/)

GONÇALVES, T. M. Cidade e Poética: um estudo de psicologia ambiental sobre o ambiente urbano. Ijuí: Unijuí. 2007. 
GRUBITS, S. A Casa: Cultura E Sociedade Na Expressão Do Desenho Infantil. Psicologia em Estudo, Maringá, v. 8, num. esp., p. 97-105, 2003.

GRUMAN, M. Caminhos da cidadania cultural: o ensino de artes no Brasil. Educar em Revista, Curitiba: Editora UFPR, n. 45, p. 199-211, jul/set. 2012.

HALL, S. A identidade cultural na pós-modernidade. Trad.Tomaz Tadeu Silva. 11a ed. Rio de Janeiro, RJ: DP\&A, 2006.

KANDISNSKY. Olhar sobre o passado. São Paulo: Ed. Martins. 1991.

KASHDAN, Todd B.; BISWAS-DIENER, Robert. A força boa do lado obscuro. 1a Edição, Rio de Janeiro: Editora Rocco, 2016.

LEENHARDT, J. Teoria e Prática do Patrimônio. In: LEENHARDT, J.; SANTOS, N. M. W.; BERND, Z. (Orgs.). Bens Culturais: temas contemporâneos. Porto Alegre: Movimento, 2011. v. 43.

LOWENTHAL, D. Como conhecemos o passado. Revista do Programa de Estudos Pós-Graduados de História, São Paulo, v. 17, p. 63-201, nov./1998.

MATHEWS, G. Cultural global e identidade visual: à procura de um lar no supermercado cultural; trad. Mário Mascherpe. Bauru, SP: EDUSC, 2002.

MORGADO, A. C. As múltiplas concepções da cultura. In: Revista Múltiplos Olhares em Ciência da Informação. № 4, v.1, mar. 2014.

MUNCK, L. ; SOUZA, R. B. O Ecletismo do Paradigma da Sustentabilidade: construção e análise a partir dos estudos organizacionais Revista de Ciências da Administração, v. 13, n. 29, p. 202-242, jan./abr. 2011.

MUSSI, L. H.; CÔRTE, B. O significado "afetivo" daquilo que chamamos "casa": uma reflexão através do cinema. In: Caderno Temático Kairós Gerontologia. № 8 , São Paulo, nov/ 2010.

OLIVEIRA, A. C. C.; MOURÃO, N. M. Memória Coletiva e Objetos Biográficos: estudo dos oratórios em Minas Gerais/Brasil do período colonial. In: Anais do II Seminário Latino-Americano de Estudos em Cultura - SEMLACult. Foz do Iguaçu: UNILA, set. 2018.

PNUD-PROGRAMA DAS NAÇÕES UNIDAS PARA O DESENVOLVIMENTO. Relatório do desenvolvimento humano, ONU, 1994.

RAPOPORT, A. Vivienda y cultura. Barcelona: Gustavo Gilli, 1972.

ROYER, J. Le Dessin d'une Maison: image de l'adaptation sociale de l'enfant. Paris: EAP Editions, 1989.

RYBCZYNSKI, W. Casa: pequena história de uma ideia. Rio de Janeiro: Record, 2002.

SACHS, I. Desenvolvimento includente, sustentável, sustentado. Rio de Janeiro: Garamond, 2008. TREINTA, F. T.; FARIAS FILHO, J. R.; SANT'ANNAC, A. P; RABELO, L. M. Metodologia de pesquisa bibliográfica com a utilização de método multicritério de apoio à decisão. Revista Produção. São Paulo, v.24, n.3, p.508-520, jul/set, 2014.

VALLEJO, César. Obra Poética Completa. Havana, Cuba: Casa das Américas, 1975. 